\title{
An Integrated Developmental Model for Poverty Reduction in South Africa: An NGO's Perspective
}

\author{
ANTOINETTE LOMBARD, MARIETA KEMP, NELIE VILJOEN-TOET, and \\ MARTIE BOOYZEN \\ Department of Social Work \& Criminology, University of Pretoria, Pretoria, South Africa
}

For most of its 17 years of democracy, South Africa fight against poverty has been fragmented and uncoordinated. South Africa adopted a developmental social welfare policy in the White Paper for Social Welfare (1997). The SAVF (South African Women's Federation), a welfare sector NGO, has designed an integrated development model for social work to address poverty holistically. The model's six pillars will be discussed, with reference to their application in the Thuthukani project. Conclusions will be based on a discussion of the value of the SAVF model in demonstrating its relevance as an anti-poverty strategy within a developmental social welfare approach.

KEYWORDS integrated development, poverty, poverty reduction, model for poverty reduction, anti-poverty strategy, $N G O$, South Africa

Address correspondence to: Antoinette Lombard, Professor in Social Work, University of Pretoria, Department of Social Work and Criminology, Humanities Building 10 - 21, Pretoria, 2001, South Africa. E-mail: antoinette.lombard@up.ac.za 
The decision by the first democratic South African to prioritise social grants as an anti-poverty strategy was a well-justified attempt to start eliminating the extreme levels of poverty and inequalities of the Apartheid past (RSA, 2008). Sen (2001) indicates that the classic view that poverty is just a shortage of income may be well-established, but poverty has ultimately to be seen as the lack of various kinds of freedoms, including the freedom to achieve minimally satisfactory living conditions. The South African government's view of poverty is in line with this approach. It regards poverty as a state of multiple deprivations, i.e. a deficiency in individuals' socio-economic capabilities, including income, access to basic services, assets, information, social networks or social capital (RSA, 2008).

It was thus inevitable that an anti-poverty social grant would be an important but inadequate effort, in the absence of exit strategies, to benefit the development and self-reliance of people who are poor (Department of Social Development, 2006). Although South Africa has made significant progress since 1994, abject poverty is still widespread and the level of inequality is deepening (RSA, 2009). Unfortunately, the war on poverty in South Africa has, for most of the 17 years of democracy, been fought in a fragmented, uncoordinated manner. Government's promise, repeated in 2011 by the President of South Africa, to link social grants with economic activity and community development so as to enable short-term beneficiaries to become selfsupporting, has yet to be fulfilled (RSA, 2011). In the face of the state's obvious lack of capacity in addressing socio-economic challenges, the social welfare sector has taken up this challenge seriously since 1997 (Dinokeng Group, 2009). Demonstrating commitment to transformation and the change to a truly democratic society, the social welfare sector adopted a development policy in the form of the White Paper for Social Welfare (RSA, 1997). A developmental approach to 
social welfare positioned NGOs such as the South African Women's Federation (SAVF) as significant partners in social development.

The approach and structure of this article is first to outline the developmental social welfare policy framework and contextualise social work as a role player in social development. Focus then shifts to SAVF and the integrated developmental model for poverty reduction it designed, including an illustration of the six pillars of the model as applied in the Thuthukani project. This will be followed by a discussion of the value of the model for developmental social work. The conclusion will present some challenges for developmental social work to reduce poverty in South Africa.

\section{Developmental Social Welfare and Social Work}

South Africa's developmental approach to social welfare evolved out of the country's unique history of inequality and the violation of human rights as a result of colonialism and apartheid (Patel, 2005). Developmental social welfare is the "name given to South Africa's new welfare system moulded by the theory of social development as embodied in the White Paper for Social Welfare ...” (Gray, 2006, p. s54). In alignment with many other authors' views (cf. Midgley, 1995; Gray, 1996; Mayadas \& Elliott, 2001; Patel, 2005; Lombard, 2007; Patel \& Hochfeld, 2008), Lombard and Wairire (2010) define developmental social work as:

an integrated, holistic approach to social work which recognises and responds to the interconnections between the person and the environment; links micro and macro practice and utilises strength-based and non-discriminatory models, approaches and interventions, and partnerships to promote social and economic inclusion and well-being (p. 100) 
Social development affirms the commitment of the social work profession to social justice and human rights, as well as to the eradication of poverty and inequality, and it positions social work as a role player and partner in the social welfare sector (Lombard, 2007) by "... promoting people's welfare in conjunction with a comprehension process of economic development" (Midgley, 1995, p. 25). Developmental social work diverges from conventional social work practice. It calls for more innovative strategies to address poverty with the aim of creating more sustainable livelihoods, while not rejecting all past practices (Hall \& Midgley, 2004; (Midgley \& Conley, 2010). In 1998, Midgley, who played a pioneering role in the developmental social welfare approach in South Africa, challenged the country's social work scholars to document and analyse their experiences in the implementation and effectiveness of a developmental approach.

The SAVF is one NGO that responded to the challenge to implement developmental social work practices. During the 1990s, the organisation proactively utilised the opportunities afforded by the new democracy and underwent major transformation in line with the new democracy. This included embracing the developmental approach to social services delivery as mandated by the White Paper for Social Welfare (RSA, 1997). Based on the practical experience of social workers, the views of service-users and empowerment programmes that had been successfully implemented over the past decade, social workers have developed an integrated developmental practice model for reducing poverty (cf. SAVF Manual, 2009). 


\section{The SAVF: Integrated Developmental Model for Poverty Reduction}

The SAVF is a social welfare NGO with 107 years of experience in working with the poor and marginalised in society. Since its inception in 1904, the SAVF has been intensely involved with the establishment of programmes that address the problem of poverty. The SAVF plays a major role in educating social work students and providing field placements. It is a volunteer-driven child- and family-focused organisation that renders general social services to individuals, families, groups, communities and organisations in both urban and rural areas of South Africa. The SAVF support values of human dignity and socio-economic rights for all people in South Africa (cf. SAVF Report on Provincial Imbizo on Transformation, 2006).

In the SAVF's view, poverty refers to persons/ families living in a situation of ongoing indigence and below the bread-line to the extent that they cannot provide for their own basic daily needs. They have minimal or no income and experience a lack of resources and skills to generate basic income, thus becoming dependent on the community (SAVF Manual, 2009). The principles undergirding SAVF's integrated, developmental model include: taking ownership and responsibility; creating independence; providing special aid and programmes for the vulnerable; civil society participation; and promoting family unity. The model has six empowerment pillars (SAVF Manual, 2009), which are discussed below. The reciprocity between the pillars emphasises the holistic, integrated nature of anti-poverty developmental strategies and programmes. In the context of the interrelatedness of poverty and freedom, the pillars of the model can be regarded as different kinds of freedoms that can strengthen one another (Green, 2009). 
The Thuthukani (Zulu word meaning to develop) youth project was initiated in 2004 in the Mamelodi township after social workers identified a high incidence of teenage pregnancy, uncontrollable youth and early school dropout. The people in this area are often unemployed because they rely on temporary jobs and thus live in poverty, and a very large proportion of the community depend on social grants. A great many community members are still under the age of 20. In line with government policy, mother-tongue education (which can be in any one of 11 official languages) is provided in the foundation phase, while from Grade 4 onwards classes are presented in English. Many children struggle with English, which has a strong negative impact on their academic performance. This challenge is exacerbated by the structural challenges these children face in their families and community struggle to escape the poverty trap. In response to these needs, third-year social work students, volunteer youth leaders from the community and educators from Legora Primary School conceptualised a prevention programme for children and their families. The programme, based at the Legora Primary School, is a community-driven partnership between social work students at the University of Pretoria, SAVF and the Mamelodi community. In contrast to government's commitment to development and preventative programmes, government funding is primarily channelled towards statutory work and the Thuthukani programme is funded by individual donors, charitable trusts and the National Lotto Distribution Trust Fund.

Thuthukani accommodates learners from grades 4 to 6 who, on an annual basis, have been referred to the project by teachers. The criteria for a referral are poverty, academic backlog due to family dysfunction or poverty, and orphan status. Children in foster care under the supervision of the SAVF are also included. In 2009, a total of 87 learners participated in the programme 
(SAVF Thuthukani Annual Report, 2009). The main activities of the project include weekly homework sessions for children to improve their academic performance and motivation to learn; quarterly outings, including an adventure camp where children get the opportunity to broaden their life experiences; a series of therapeutic group-work sessions focusing on life skills, resilience and self-esteem; meals during homework sessions; a credit system, based on attendance of the homework sessions that allows for the purchase of school uniforms; and parental guidance and family services. The next section discusses the model's six pillars and how SAVF regards them. The Thuthukani project will be integrated into the discussion to demonstrate how the model is applied in practice within the boundaries of one programme.

\section{Promotion of Economic Well-being}

Social workers hold different opinions on their responsibility in economic activities (cf. Midgley, 2010). The SAVF argues that social workers are directly involved in serving people who have, at the core of their existence, social problems that are so intertwined with economic problems that they cannot separate the two. This pillar provides services on a continuum, ranging from material assistance to training and networking, to income-generating projects. Material assistance includes, inter alia, a clothing bank, provision of domestic articles and assistance in accessing social grants and pensions. Social assistance, however, is always provided within the context of fostering independence on the part of the recipient. Recipients are introduced to the range of services and programmes available in the respective pillars, and are allowed the freedom to indicate where they would engage in moving towards self-reliance. In addition, the model encourages attempts to seek work, and service-users are required to show evidence of registration at employment agencies. Furthermore, social workers network with training centres 
such as the Departments of Labour and Trade and Industry regarding services they deliver relating to employment-creation and skills-training. They maintain a database of work-seekers and employment organisations in order to match relevant working opportunities with appropriate skills. In addition, they facilitate youth employment by investigating possibilities for children in children's homes so that they can find work when they leave school.

Income-generating programmes and job-creation are stimulated in areas of existing talent or interest, such as bead-work, cleaning businesses, poultry projects, woodwork and recycling projects. The SAVF facilitates training in business skills, including budgeting and marketing, and is thus directly involved in economic literacy which Engelbrecht (2008) regards as a critical aspect for social work beneficiaries. Support is also provided in terms of finding a market for products, for example the Crafé@SAVF market outlet point on the SAVF premises, and the initiative promotes quality, because inferior products are not sold. This pillar also stimulates resource development within the organisation, by encouraging income-generating products that can benefit the organisation, such as a project providing linen for the SAVF's children's homes.

The economic pillar is embedded in community-development initiatives and activities that require a deliberate commitment to this method and strategy, in addition to individual- and family-focused programmes. Midgley and Conley (2010) argue that community social workers need to be directly involved in economic development projects that contribute to poverty alleviation. Harris's experience is that about 90 percent of successful community (economic) enterprises have first gone through a community development process, and therefore, in his view, 
"the distinction between community business oriented groups and those with a social-service function is largely one of degree" (Harris, 1998, p .36).

The Thuthukani project addresses material and economic needs. Both learners and parents/caregivers are informed about their rights to social security. To protect the learners against a culture of dependency through hand outs, their need for clothes and school stationery is addressed by an annual sale at which learners can buy school uniform items, blankets and stationery with the credits they have earned through regular attendance of homework and groupwork sessions. Attendance of these sessions is voluntary, so earning credits is a choice and a selfdriven activity. Learners are responsible for calculating what they need and what they can afford according to their credits. They then place their orders and purchase the clothes on delivery. By taking part in this initiative, they learn the value of economic literacy on a small scale. The fact that they manage the entire process by themselves instils in them self-confidence, pride and dignity. The average attendance is 78 children (89\%) per afternoon (SAVF Thuthukani Annual Report, 2010). Even when school unexpectedly closes early, the children wait for the homework sessions. The SAVF also facilitates a jumble-sale (second-hand articles sale) programme that engages the families and broader community. Social work students collect quality second-hand clothing and household items, which are sold for R5 (less than \$1) at sales where parents and community members can buy according to their needs. Funds raised in this way are ploughed back into the school uniform and food budget fund. These jumble sales are very popular and are well-supported by the community. 


\section{Improvement of Health}

Children's right to healthcare services includes a range of other services as well, such as water, sanitation, nutrition, education and social services, which are needed to obtain optimal development (Kibel, Lake, Pendelbury \& Smith, 2009/2010). The health of poor people is subject to daily attrition from dirty water, malnourishment and a lack of basic health services (Green, 2009). The health pillar makes provision for food parcels and feeding schemes, again based on the principle of facilitating independence. Children of poor parents are subject to different stresses in different environments (Govender, 1998). Rogge (2000) identifies the combined effects of economic and environmental problems as risk factors for children who are poor. The health pillar also covers health rights, including education on basic eating and healthy food; encouraging people to set up food gardens; basic hygiene; clean drinking water; sanitation; and immunisation; HIV and sexually-transmitted diseases; and environmental care programmes (cf. Gonzalez, 1998).

In the Thuthukani project, this pillar includes feeding schemes, referrals and food gardens. The project provides a balanced lunch on homework afternoons and meals on outings. These meals supplement the daily feeding scheme managed by the school during school hours. Sachs (2005) affirms that providing meals for all the children at the primary school could improve their overall health, as well as the quality of education and school attendance. The school also maintains a food garden where unemployed parents can grow vegetables to sell. Parents often neglect hearing and visual conditions that cause serious barriers to learning, but when such challenges are identified, the children are referred for treatment. The school follows a prescribed protocol for children who are known to be HIV-positive. Nurses are engaged to tell the children about 
health issues and puberty. Although more initiatives are needed to counteract the environmental degradation, such as waste management initiatives, the food garden project is a starting point that shows how a change in the environment has a positive effect on "their human development and their ability to take control of their lives and the processes that shape their destiny" (Zwane, 1998, p. 8).

\section{Improvement of Education}

The inter-relatedness of education with the model's other pillars emphasises human development as the foundation of anti-poverty strategies and interventions. Cheston and Kuhn (2002, p. 64) capture it aptly: "As it is often said, knowledge to the poor is power to the poor... illiteracy creates a situation of dependency on others that can limit an individual's prospects for empowerment.". The adult literacy rate in South Africa for the period 2005 to 2008 was $89 \%$ (UNICEF South Africa, n.d.). This pillar thus focuses on both children and adults and underpins what Neilson and Gray (1997) refer to as educational empowerment, which ranges from pre- and after-school care, to bridging education, basic adult education, and skills training in community development-related activities such as pre-school education, literacy training, marketing and bookkeeping. The implementation of holistic early childhood development programmes is one of the most effective ways of redressing the gross societal inequalities caused by the legacy of apartheid, including children without access to clean water proper sanitation, nutrition, healthcare or educational facilities (Johnson, 1999). However, the majority of young children in South Africa do not have access to quality early childhood development centres because of poverty. SAVF programmes for children include life-skills programmes delivered by means of puppet shows; after-school care facilities; promotion of libraries at children's homes; creation of 
toy libraries; holiday programmes; buddy projects in which children care for each other; and career guidance. Volunteers assist with transport to school and sport, and community members are trained to assist children, including those with learning problems, with homework. Sponsors are recruited to take responsibility for a particular child's education or for developing a day-care facility. Training and employment opportunities are created for school leavers. Sponsors are also recruited to train learners in Information Technology and the development of Information Technology centres at schools. One of the two hallmark SAVF empowerment programmes that underpin this pillar is the Botswadi (being a parent) parenting guidance programme, which was launched in 1992 and is offered in four languages. It is available not only to parents, but also to people who work with children. The other programme is the Ama-jôl-jôl (play-play) programme launched in 1998, which is a 30-page illustration programme developed for people involved in handling informal play groups for pre-school children.

In the Thuthukani project early academic underachievement, acceptance of failure as a norm, absence of homework supervision, a lack of motivation to achieve and poor self-esteem all play an important role in learners' overall performance, and are addressed in the homework sessions. With regard to the effect of poverty on academic achievement, Pellino (n.d.) states that poor children generally achieve at lower levels, which can be attributed to numerous causes related to both the social environment in which they live and the education they receive in school. Fleisch (2007, p. 60) adds: "Family poverty sets in motion a chain of events that together create intractable impediments in the way of school achievement." 
During homework sessions, second-year education students assist in improving academic performance, encouraging the learners to participate actively in this process. The accomplishment of doing homework creates pride and confidence in learners. Apart from making sure that the homework is done, the students also address areas in which the learners are experiencing backlogs, for example in mastering English. As English is the medium of instruction from Grade 4 onwards, improvement in English unlocks children's potential to perform better in other subjects, such as social sciences, life orientation, natural science, mathematics, technology, and art and culture. The learners expressed their need to have homework sessions every day, as it helps them to improve their schoolwork. An analysis of the learner-evaluation in 2009 indicated that the majority of the learners have improved in their reading performances. To evaluate the impact of the homework sessions on the learners' scholastic performance, their reading ages were assessed in April and September 2010. Results showed that 86.4 percent of the children's reading ages improved by an average of two years and three months in the six months between the pre- and post-test (SAVF Thuthukani Annual Report, 2010). Learners also indicated that their parents valued the Thuthukani project because it was encouraging them to acquire new knowledge and skills.

Three unemployed parents and three SAVF volunteers from the greater Mamelodi community assist on a voluntary basis as food and homework managers. They accompany the children on outings and carry out the role of mothers, taking care of the children when they are involved in the project. The volunteers' involvement is the result of training, the development of selfconfidence, and finally being empowered to take over these roles. According to Motlhaolwa (2001, p. 28) self confidence means "that people are aware of their own knowledge and skills ... 
[and] ... at the end of an intervention are confident in themselves, their ability to think and their capacity to initiate and implement." They receive a R50 (\$7) stipend per homework session. Their involvement thus focuses not only on building the capacities leading to self-confidence and empowerment, but also on promoting their economic well-being. The volunteers from the community now transfer their knowledge and skills by training other people in the community to assist as volunteers.

\section{Empowerment towards Positive Self-assertion}

This pillar prepares children and adults to assert themselves in any situation in which they may find themselves by making sure that they know their rights, and that they are kept informed and are fully involved in decisions that affect them. Women and children are particularly vulnerable. The empowerment of women at the individual level helps build a base for social change, while empowerment at their income level can increase women's status in their families and societies (Cheston \& Kuhn, 2002).

Self-assertion programmes include providing information on applying for identity documents and birth certificates to provide access to social grants based on recognition of socio-economic rights; training domestic workers in basic home management; influencing policies that protect women; presenting literacy and financial literacy programmes and procedures; training people in basic management skills; developing leadership; offering assistance in preparing a curriculum vitae; giving training in basic office skills, such as how to use a telephone and send a fax; and giving guidance on how to complete forms (e.g. for identification documents or funding proposals) and how to share relevant information to ensure informed decision-making. The aim 
of these activities is to build self-esteem and confidence, which lead to empowerment and selfassertion. Cheston and Kuhn (2002, p. 41) state that "self-confidence is one of the most crucial areas of change for empowerment...” In the context of participation, Mokgohloa (1995, pp. 2-3) regards empowerment as a "process in which people discover their potential, develop new knowledge and a process of asserting themselves ... [and] ... where people should feel bold, confident and less afraid of criticism."

Children from poor households, such as those in the Thuthukani project, frequently perceive themselves as unworthy and unimportant. They feel disempowered and unsafe, which is a stumbling block to learning. Basing their approach to the expressed needs of the learners, social work students developed a group-work programme with a long-term goal: To help learners not to define themselves as poor, but to encourage them to dream and shape their own future. Group discussions include themes that facilitate the following on the part of the children: acceptance and appreciation of themselves; belief in their own power to make choices that could change aspects of their lives; development of time-management skills, which could help give them more control over their lives; identifying, understanding and dealing with their feelings more effectively; how to construct positive messages to themselves and others; building relationships and identifying people they can trust; uncovering the hope that they could achieve; and the ability to overcome problems and be a good role model for others. McDonald (2009) argues that children's poverty and its impact on their identity matters from a very early age and that "their experience of poverty and its impact on their identity is as much a function of their reading of themselves as it is of other's reactions to them" (p. 14). Children with a positive self concept are 
usually "more successful academically, have more self-confidence and are socially better adjusted" (Louw \& Louw, 2007, p. 183).

Quarterly outings and annual camps provide opportunities for children to have fun and broaden their horizons. The adventure camp focuses on the discovery of strengths in a fun way. For the majority of these children, the camp is their first and only holiday. Sleeping in brick rooms (as opposed to informal shacks), enjoying hot showers and sitting down to three full meals per day is an unusual experience for them. Feedback from the learners in terms of their learning experiences showed that they appreciated, inter alia, learning about animals and the environment; creating something, for example, in paper maché; learning how not to be scared, how to listen, how to respect others, and how to work as a team and take care of themselves (SAVF Thuthukani Annual Report, 2010). These events showed the children that they are noticed and admired, which, in turn, creates self-esteem (Bruwer, 2001) and confidence to be assertive.

\section{Promoting Personal Status and Dignity}

The Bill of Rights of the South African Constitution (1996) states that everyone has inherent dignity and the right to have their dignity respected and protected. This pillar is founded on the principles of non-labelling; respect for values; co-responsibility; recognition; empathy and professional conduct. The pillar requires a shift from labelling concepts such as 'children from children's homes', 'HIV/ AIDS orphans'; 'beggars'; 'welfare cases'; 'poor people' and 'street children', which keep people excluded and marginalised. The poor "is not a homogenous mass nor are they always merely weak, passive recipients of government handouts" (Hall \& Midgley, 2004, p. 7). Lombard (2003, p. 227) concurs that being poor does not mean that people do not 
have the will, hope and strength to initiate and/or actively participate in interventions that can improve their lives. Further, this pillar includes demonstrating respect by never talking down to people from a position of authority; it gives recognition to people for any progress made towards change and guides them to take responsibility. It also facilitates the development of leadership qualities; compassion and consideration, especially in cases where people have little or no sense of self-worth, and identifies people's strengths in order to instil trust, faith and dignity within them. In line with these principles, social work interventions and programmes are guided by the profession's ethical code and international and national declarations such as those for the aged and children.

Programmes that promote this pillar include establishing support groups; outreach programmes like adopting a granny, a family or a child; creating a burial fund for people to ensure a dignified funeral; and opportunities for children to be introduced to and learn about other cultures, their practices, habits and dress codes in order to develop respect for different cultures and diversity, and to cultivate self- and reciprocal respect for their own and others' views by facilitating discussion opportunities/group discussions on controversial issues. The programmes further include those on personal appearance, where people are guided on their own appearance and how to present themselves convincingly for job interviews, for example. Treating people with dignity features strongly where people in need are assisted with clothing. Being poor does not mean that people are expected to wear simply anything that fits. Children in particular must be socially included by means of contemporary fashion standards in both clothing and hair styles. Positive feelings about their own appearance help to instil pride and self-worth in people of all ages. 
This pillar also applies to the SAVF as an organisation and its staff. Facilities and amenities where services are rendered must be accessible and must make service-users feel welcome. Services must be aligned with the needs of the target groups and reflect high standards. Being poor does not mean that people cannot define their own needs (cf. United Nations, 1999), know what is best for them or take ownership of their own development. What they need is to be treated with dignity and respect and be provided with opportunities and support to explore and build on their strengths, which will facilitate self-reliance. This means that conceptualisation, direction, implementation and evaluation of any initiative should be by those it was established for (Motlhaolwa, 2001). Quality service delivery requires regular in-service training; empowerment through subject reading and academic debates and through opportunities to equip staff to respond to service-users with empathy and dignity. Quality service-rendering also implies that services must be brought to the people. The welfare sector cannot respond to every need, but can facilitate connections to services; for example by creating awareness among the responsible authorities of the condition of roads, the availability of transport, and the lack of water provision and funeral facilities. These are all related to infrastructure and assets in communities, which are all-important in anti-poverty strategies. The personal appearance of staff and professionals when it comes to appropriate dress codes and presentation is equally important in making service-users feel respected.

The learners in the Thuthukani project are very proud of their involvement. The individual attention and opportunities make them feel very special. All the activities focus on improving their self-esteem and giving them hope that they can reach their full potential. The clothing sales provide the children and their parents with the opportunity to purchase items that they would not 
otherwise be able to afford. This is done without labelling or stigmatising them as being dependant on charity. Correct, neat school uniforms add to their dignity and status among the other children in the school. Being able to go to school with completed homework makes the children feel proud and give them the confidence to participate in class. In this way the project facilitates social inclusion. Parents involved as volunteers grow in self-confidence, which is reinforced by the recognition they receive for the work they do. The group-work series strengthens their ability to overcome adversity. The learners receive certificates for their involvement during a school opening ceremony, which furthers their sense of self-worth.

The parents' attitude towards the project is very positive and they encourage their children to attend. However, early attempts to involve them in parent guidance activities failed, so a new approach was followed in 2010. The parents were invited to enjoy the outings with their children, which resulted in more successful motivation to be actively involved in their children's education. Their involvement not only provides an opportunity for gaining information and knowledge, but also transfers to skills to assist their children at home with their homework. In turn, the parents become confident and more empowered, which leads to further involvement in other activities at school and in the community. Birkett (1998, p. 18) emphasises the importance of this: "Make sure that your [social work] intervention empowers the parent ... The parents are the first and most effective educators of their children, but they might need your [the social worker's] understanding, encouragement and input." 


\section{Promoting the Protection of the Most Vulnerable}

This pillar refers to SAVF's responsibility to promote the reduction of the life-risks to vulnerable people. According to Green (2009, p. 201), vulnerability describes the reduced ability of some communities or households to cope with the events and stresses to which they are exposed. The opposite of vulnerability, he argues, is security. This pillar thus combines protection and security. It includes providing programmes in child protection, victim empowerment and crisis intervention. It also includes prevention programmes for safety measures at home, programmes on handling conflict and programmes on community care. Child protection programmes include crèches, adopting a cop (police officer) and presenting puppet shows on abuse and molestation; how to respond to child, drug and alcohol abuse and violence; how to prevent crime; and sexual defence programmes for children. This pillar requires knowing and implementing all the relevant policies and legislation, but also challenging and influencing policy development in relation to protection issues, in particular for children, women and the aged. It further implies informing and educating vulnerable groups on their rights, as enshrined in the Bill of Rights in the South African Constitution (1996) and in other legislation, policies and declarations. Most importantly, service-users are prepared and mobilised to have their voices heard in influencing policies and legislation.

Social services, including individual and family counselling and child protection services rendered by the social work students and the SAVF social workers, provide a safety network for the children in the Thuthukani project. Because parents build relationships with teachers, social workers and social work students through the project, it gives them the confidence and opportunity to seek help when needed. Children in poor communities are also vulnerable to 
physical neglect and abuse. During the project, they are informed of their rights and empowered to assert themselves against abuse. Homework and group-work sessions provide an opportunity to communicate their concerns in a safe context, which is followed up by education and/or social work students.

\section{Discussion}

South Africa has come a long way since 1998 when Zwane reported that "The present perception in the townships of a social worker is that of a food parcel delivery" (1998, p. 7) and Midgley (1998) challenged scholars to conceptualise and implement developmental social work. The SAVF model demonstrates its relevance as an anti-poverty strategy within a developmental social welfare approach. It is people-centred and embraces a rights-based approach, which is, according to Green (2009, p. 504), “[a]n approach to human development that unites economic and social rights with political and civil rights, aiming to build a social contract between state and citizen; [an] approach built on the idea' that all people are of equal dignity and worth, and have natural rights but also responsibilities towards their communities." The cross-cutting themes of the model's pillars show that anti-poverty strategies are about human dignity and empowerment; about having a voice. Sachs (2005), after meeting with the urban poor in Mumbai, India, affirmed:

The overarching theme of our discussion is not latrines, running water; and safety from the trains, but empowerment: specifically, the group is discussing how slum dwellers who own virtually nothing have found a voice, a strategy for negotiating the city government. What they need is skills to negotiate for what they want... (p. 239). 
The SAVF model is designed to focus on micro and macro issues in the development of individuals, families and communities and to facilitate their self-reliance through capacity building and empowerment. The inclusive social work focus of the model poses a challenge to government in terms of funding anti-poverty programmes. This is more important in view of the worldwide evidence that poor people can both pay back loans and save (Larance, 2001; Thin, 2002). Government should seriously investigate innovative funding strategies, which NGO welfare organisations could administer on their behalf. They could, for example, rather than giving a once-off subsidy, which would amount to fostering dependency, allot funds to the SAVF to be used at their own discretion as a revolving fund for supporting income-generating projects. It is therefore important that government adopt an anti-poverty strategy that will provide an enabling environment (cf., Yunus, 2007) for NGOs to implement integrated developmental strategies.

The model provides significant evidence that the role of social welfare/social work as a partner in social development is much broader than that of just providing safety nets and protection for the vulnerable as a human right. Within a developmental approach, social workers commit themselves to empowerment and participatory strategies that integrate human, social and economic development. Midgley and Conley (2010) outline how social workers can influence human, social and economic capital development in both a direct and indirect manner. The integrated developmental model of the SAVF reflects most of the proposed interventions. Influencing the economy in an indirect way includes: empowering and supporting local people in communities in handling problems on racism, discrimination, and exploitation by educating them about these issues; challenging exploitative and oppressive power structures; supporting the 
expansion of education, nutrition, health, access to medical care, maternal and child health services, family planning; adequate day care services that not only facilitate the employment of parents but generate human capital through preschool education, nutrition, and medical services. Social workers can contribute to direct community economic development by supporting local people in establishing a variety of economic projects, including cooperative micro-enterprises, savings associations, afterschool homework classes, adult literacy classes, day-care centres, job training and job referral programmes provided by non-profit organisations (Midgley \& Conley, 2010).

The SAVF model affirms the importance of integrated social and economic policies in achieving anti-poverty outcomes and the importance of service-users' voices in this process. Neilson and Gray (1997, p. 32) affirm that social policy "must help to develop human capacity and human resources and must be linked directly with economic development measures." From the above discussion, it can be concluded that the model reflects the key themes for developmental social welfare: the rights-based approach; the interrelation between social and economic development; democracy and participation in development; the relevance of partnerships; and reconciling the micro-macro divide (Patel, 2005).

The SAVF model provides a best practice African model which poses a challenge to the rest of the world to design similar anti-poverty models based on integrated socio-economic pillars relevant to the country specific poverty context. The developmental nature of the model challenges social workers to embrace their role in addressing the multi-faceted nature of poverty through innovative social and economic strategies. 


\section{Conclusion}

Social workers have a clear mandate in the White Paper for Social Welfare (RSA, 1997) to implement developmental social welfare and have fully embraced the challenge to implement the development approach. Despite having made good progress through best practice models such as the SAVF, many challenges exist, including that of acknowledging the role of social work in poverty reduction through direct economic contributions. A starting point is that social workers do away with the self-inflicted marginal perception of their role in poverty and social development (cf. Engelbrecht, 2008). This is now made easier with the recognition that social work programmes have a social investment function that contributes positively to development (Midgley \& Conley, 2010).

The SAVF model demonstrates that NGOs in the social welfare sector and social workers can be significant change agents in adding value in the form of transformational change that will benefit disadvantaged communities and ultimately society at large (Botha, 2009). The model brings hope and dignity to poor people with the opportunity to be recognised as contributing positively to their own and the community's well-being, as opposed to being thought of as consumers of scarce public resources (Raheim, 1996). The model demonstrates that vulnerable people are 'far from passive and are constantly seeking ways to prepare for and cope with the daily risks that surround them' (Green, 2009, p. 204). The model concurs with what Green (2009, p. 210) describes as:

[a] maturing understanding of the nature of poverty, with its growing attention to issues of rights, dignity, and empowerment, and the recognition that inequality and 
social exclusion are not just damaging in themselves but hold back economic progress ... 


\section{References}

Birkett, P. (1998). Stepping in between disability and handicap. ChildrenFirst, 2(18), 16 - 19.

Botha, M. (2009). The entrepreneur. In Nieman, G. \& Nieuwenhuizen, C. (Eds.), Entrepreneurship. A South African perspective (2 ${ }^{\text {nd }}$ ed.) (pp. 29-51). Pretoria, South Africa: Van Schaik Publishers.

Bruwer, E. (2001). Beggars can be choosers. In search of a better way out of poverty and dependence. Pretoria, South Africa: Institute for Missiological and Ecumenical Research (IMER), University of Pretoria.

Cheston, S., \& Kuhn, L. (2002). Empowering women through microfinance. In Daley-Harris, S. (Ed.) Pathways out of poverty. Innovations in microfinance for the poorest families (pp. 167-228). Bloomfield, CT: Kumarian Press, Inc.

Constitution of the Republic of South Africa, 1996 (Published in the Government Gazette, (17678) Pretoria, South Africa: Government Printer.

Department of Social Development. (2006). Linking social grants beneficiaries to poverty alleviation and economic activity. Discussion document, 1 November.

Dinokeng Scenarios. (2009). 3 Futures for South Africa. Available at: www.dinokengscenarios.co.za.

Engelbrecht, L. (2008). Economic literacy and the war on poverty: A social work challenge. International Journal of Social Welfare, 17(2), 166-173.

Fleisch, B. (2007). Primary education in crisis. Why South African schoolchildren underachieve in reading and mathematics. Cape Town, South Africa: Juta. 
Gonzalez, J.L. (1998). Development sustainability through community participation. Mixed results from the Philippine Health Sector. Aldershot, England: Ashgate Publishing Limited.

Govender, K. (1998). Infections drain energy and ability. ChildrenFirst, 2(18), 9- 11.

Gray, M. (1996.) Towards an understanding of developmental social work. Social Work Practice, $1.96,9-13$.

Gray, M. (2006). The progress of social development in South Africa. International Journal of Social Welfare. 15 (Supl), S53-S64.

Green. D. (2009). From poverty to power. How active citizens and effective states can change the world. Johannesburg: Jacana Media with Oxfam International.

Hall, A., \& Midgley, J. (2004). Social policy for development. London, England: SAGE Publications.

Harris, K. (1998). Problems in community enterprise and community economic development. In Twelvetrees, A. (Ed.). Community economics. Rhetoric or reality? (pp. 36-42). London, England: Community Development Foundation.

Johnson, K. (1999). Pre-school provision still a class issue. ChildrenFirst, 3(23), 30-33.

Kibel, M., Lake, L., Pendelbury S. \& Smith, C. (Eds.). (2009/2010). South African Child Gauge. Children's Institute. Cape Town: University of Cape Town.

Larance, L.Y. (2001). Fostering social capital through NGO design. International Social Work, 44(1), 7-18. 
Lombard, A. \& Wairire, G. (2010). Developmental social work in South Africa and Kenya: Some lessons for Africa. The Social Work Practitioner-Researcher, Special Issue: Toward an African Social Development Research Strategy. April 2010, 98-111.

Lombard, A. (2003). Entrepreneurship in Africa: Social work challenges for human, social and economic development. Social Work/ Maatskaplike Werk, 39(3), 224-239.

Lombard, A. 2007. The impact of social welfare policies on social development in South Africa: An NGO perspective. Social Work/ Maatskaplike Werk, 43(4), 295-316.

Louw, D., \& Louw, A. (2007). Child and adolescent development. Bloemfontein, South Africa: Psychology Publications.

Mayadadas, N.S., \& Elliott, D. (2001). Psychosocial approaches, Social work and social development. Social Development Issues, 23(1), 5-13.

McDonald, C. (2009). Children and poverty. Why their experience of their lives matter for policy. Australian Journal of Social Issues, 44(1), 5-21.

Midgely, J. (1998). Social development and social welfare: South Africa in an international context. Social Work/ Maatskaplike Werk, 34(1), 90-98.

Midgley, J. \& Conley, A. (2010). Introduction. In J.Midgley \& A. Conley (Eds.). Social work and social development. Theories and skills for developmental social work (pp. xiii-xx). NY: Oxford University Press.

Midgley, J. (1995). Social Development: The developmental perspective in social welfare. London, England: SAGE Publications. 
Midgley, J. (2010). Community practice and developmental social work. In J.Midgley \& A. Conley (Eds.). Social work and social development. Theories and skills for developmental social work (pp.167-204). NY: Oxford University Press.

Mokgohloa, T. 1995. Empowerment: A people-driven process. Social Work Practice, 1.95, 2-4.

Motlhaolwa, P. (2001). Who's got the power? ChildrenFirst, 5(36), 27- 29.

Neilson. D. \& Gray, M. (1997). Integrating social development into child welfare services. Social Work Practice, 2.97, 32-37.

Patel, L. \& Hochfeld, T. (2008). Indicators, barriers and strategies to accelerate the pace of change to developmental welfare in South Africa. The Social Work PractitionerResearcher/ Die Maatskaplikewerk Navorser-Praktisyn, 20(2), 192-211.

Patel. L. (2005). Social welfare and social development in South Africa. Cape Town, South Africa: Oxford Publishers.

Pellino, K.M. [n.d.]. The effect of poverty on teaching and learning. Retrieved from http://www.teach-nology.com /tutorials/teaching/poverty/htm

Raheim, S. (1996). Micro-enterprise as an approach for promoting economic development in social work: Lessons from the Self-Employment Investment Demonstration. International Social Work, 39(1996), 69-82.

Republic of South Africa. (1997). Ministry for Welfare and Population Development. 1997. White Paper for Social Welfare. Notice 1108 of 1997. Government Gazette, 386(18166). Pretoria, South Africa: Government Printers. 
Republic of South Africa. (2008). Towards an anti-poverty strategy for South Africa. A discussion document, retrieved from, http://www.info.gov.za/view/DownloadfileAction?id=92543

Republic of South Africa. (2009). State of the Nation Address of the President of South Africa, Kgalema Motlanthe. Joint sitting of Parliament. Cape Town, South Africa. 6 February.

Republic of South Africa. (2011). State of the Nation Address by his Excellency, J.G. Zuma, President of the Republic of South Africa. Joint sitting of Parliament. Cape Town, South Africa. 10 February.

Rogge, M.E. (2000). Children, Poverty and environmental degradation: Protecting current and future generations. Social Development Issues, 22 (2/3), 46-53.

Sachs, J. (2005). The end of poverty: How we can make it happen in our lifetime. London, England: Penguin Books.

SAVF (South African Women's Federation). (2006). Report on provincial Imbizo on transformation. Available on request from: nviljoen-toet@savf.co.za

SAVF (South African Women's Federation). (2009). Thuthukani annual report. Available on request from: nviljoen-toet@savf.co.za

SAVF (South African Women's Federation). (2010). Thuthukani annual report. Available on request from: nviljoen-toet@savf.co.za

SAVF (South African Women's Federation). 2009. SAVF manual for combating poverty. Empowerment programmes. April. Available on request from: nviljoen-toet@savf.co.za

Sen, A. 2001. Development as Freedom. UK: Oxford University Press. 
Thin, N. (2002). Social progress and sustainable development. Bloomfield, CT: Kumarian Press, Inc.

Unicef, South Africa. [n.d.]. Statistics. Retrieved from http://www.unicef.rg/infobycountry/southafrica_statitics.html\#77

United Nations, (1999). Department of Economic and Social Affairs. Division for Social Policy and Development. Participatory approaches to poverty alleviation in rural community development. World Summit for Social Development. New York: United Nations.

Yunus, M. (2007). Creating a world without poverty. Social business and the future of capitalism. New York, NY: Public Affairs.

Zwane, W. (1998). The challenge is to change ourselves. ChildrenFirst, 2(18), 6-8. 